\title{
The influence of technological factors on electrochemical characteristics of cast magnesium cathodic protective elements
}

\author{
V. Kechin, ${ }^{1 *}$ E. Lyublinski ${ }^{2 * *}$ and A. Kireev ${ }^{1}$ \\ ${ }^{1}$ Vladimir State University, ul. Gor'kogo, 87, Vladimir, 600000 Russian Federation \\ ${ }^{2}$ COR/SCI, LLC, 6421 Dorset Ln., Solon, OH 44139, USA \\ *E-mail:kechin@vlsu.ru \\ **E-mail: elyublinski@gmail.com
}

\begin{abstract}
Cathodic protection systems with magnesium cast sacrificial anodes are widely used for corrosion protection of metallic structures in sea water and soil. The accumulated experience in the application testifies to the dispersion of current capacity (CC) values up to $20 \%$. As a result, the service life and economic efficiency of protection is unpredictable. Magnesium alloys have low CC (45-60\%). Studies have revealed that uncontrolled content of oxygen and hydrogen play an important role in stabilizing the $\mathrm{CC}$ of magnesium alloys. Oxygen present in magnesium alloys in the form of suspended oxide inclusions changes the basic electrochemical properties of anodes. In open melting, the oxygen content (in terms of $\mathrm{MgO}$ ) in magnesium melts is $0.001-0.02 \%$. It has been established that the alloy components should contain less than $0.01 \%$ of oxygen to ensure maximum and stable CC. The solubility of hydrogen in the interaction with magnesium leaps in the transition of metal from liquid to solid state, contributing to the formation of gas porosity in the cast metal. The increase of hydrogen content in magnesium melts from 5 to $28 \mathrm{~cm}^{3} / 100 \mathrm{~g}$ leads to reduction of CC values from 1310-1340 to $1100-1260 \mathrm{~A} \cdot \mathrm{hr} / \mathrm{kg}$. A similar result was observed on the change of the magnesium alloys $\mathrm{CC}$ depending on the gas content. It is also established that the morphology of the crystalline structure of the cast sacrificial anodes has a significant influence on the stabilization of the magnesium alloys' CC. It is shown that the crushing of the cast structure of magnesium anodes from high purity alloys of the $\mathrm{Mg}-\mathrm{Al}-\mathrm{Zn}$ system provides not only maximum CC values but also reduces the spread of these values. Thus, in order to improve and stabilize the main electrochemical properties of the sacrificial anodes, technological processes have been developed that ensure in the process of the production of anodes the control of the required purity of melts on the maximum allowable content of cathodic impurities $(\mathrm{Fe}, \mathrm{Cu}, \mathrm{Ni})$ and the restriction in the process of melting oxide inclusions and hydrogen with the mandatory conditions of casting, ensuring the grinding of the structure of cast anodes.
\end{abstract}

Key words: magnesium, compounds, impurities, structure, electrochemical properties. 


\section{Introduction}

Corrosion of metals leads to huge losses of both natural resources and material means. The annual loss of metals due to the corrosion is about $30 \%$ of their annual production, from them about $10 \%$ is lost irrevocably [1-8]. For protection against electrochemical corrosion of metal structures and constructions, cathodic protection systems with sacrificial magnesium, aluminum and zinc anodes became widely used. According to various countries, the use of this type or cathodic protection systems enhances the technical and economic performance of marine vessels, underground pipelines and other metal structures and structures, increases the service life and inter-repair periods of their operation. This corrosion protection technology reduces the thickness and mass of metal structures, decreases the labor intensity and cost of work related to the provision of corrosion protection means. The importance of protective protection increases even more with the increase in tonnage of vessels and the duration period of their operation, as well as with the increase of the network of trunk oil pipelines.

Efficiency of the practical use of protective materials for protection of metal structures from sea and soil corrosion depends on the sacrificial anodic alloy's specific properties and characteristics, availability and condition of paint coatings and insulating materials, temperature, composition and properties of the corrosive environment, and it is determined by the following criteria:

- Stability in time of the negative potential of sacrificial anodic alloys at wide modes of anodic polarization;

- High and stable actual current output, providing minimum possible non-productive losses of alloys and the longest life of the anodes;

- The minimum inclination of alloys to self-dissolution and the possibility of their effective use in combination with paint and insulating coatings;

- Optimum forms and sizes of anodes, providing the optimum value of a current, a surface area of a protective action and the specified service life of corrosion protection.

The most important indicators determining the efficiency and practical applicability of metals as the basis of sacrificial anodic alloys - materials (SAM) are their stationary $(\varphi S)$ and working $(\varphi \mathrm{P})$ potentials. Moreover, if the values of $\varphi S$ approximate the possibility of using metal as the basis of the SAM, the values of the working potential give the final answer to this question. According to the basic criteria, the specific parameters and requirements to the SAM (material) taking into account the operating conditions, the use of aluminum, magnesium and zinc was found as the basis of the SAM. The basic physicochemical properties and electrochemical characteristics of metals-bases of SAM are given in Table 1.

It is known (Table 1) that magnesium has the most negative stationary potential compared to aluminum and zinc, which indicates its preference for use as the basis of protective alloys in low-conductivity corrosive environments, such as soil and some seas. However, comparison of values of theoretical and actual current output, determining the 
coefficient of useful use of material of protectors, testify to the lowest values of $\mathrm{CC}$ for magnesium, then for other metals-bases of protective alloys.

Table 1. Properties and average characteristics metal-bases of SAM.

\begin{tabular}{|c|c|c|c|c|}
\hline \multicolumn{2}{|c|}{ Indicators } & Al & $\mathbf{M g}$ & $\mathbf{Z n}$ \\
\hline \multicolumn{2}{|c|}{ Atomic mass } & 27.0 & 24.3 & 65.4 \\
\hline \multicolumn{2}{|c|}{ Density, $\mathrm{g} / \mathrm{cm}^{3}$} & 2.70 & 1.74 & 7.10 \\
\hline \multicolumn{2}{|c|}{ Melting temperature, ${ }^{\circ} \mathrm{C}$} & 650 & 658.8 & 419.5 \\
\hline \multicolumn{2}{|c|}{ Stationary potential in sea water, $-\varphi_{\mathrm{S}}, \mathrm{V}$} & 0.56 & 1.40 & 0.82 \\
\hline \multirow{2}{*}{$\begin{array}{c}\text { Current output, } Q, \\
\text { A } \cdot \mathrm{hr} / \mathrm{kg}\end{array}$} & Theoretical & 2980 & 2200 & 820 \\
\hline & Actual & 2500 & 1100 & 800 \\
\hline \multicolumn{2}{|c|}{ Current capacity $(\mathrm{CC}), \%$} & 84 & 50 & 97 \\
\hline
\end{tabular}

The given information testifies to actuality of works connected with increase and stabilization of the magnesium alloys in the direction of search of new compositions of alloys with reduced content of cathode impurity elements, gases and non-metallic Inclusions, as well as by improving the technology of melting and casting, providing a homogeneous structure of metal.

\section{Magnesium alloy compositions}

It is well known that aluminum and zinc are used as the main alloying components in magnesium alloys [9-13]. The experience of using magnesium anode to protect metal structures from electrochemical corrosion shows that in operating conditions $\mathrm{Mg}-\mathrm{Al}-\mathrm{Zn}-$ Mn alloys, having close values of working potentials, differ significantly in their CC values (Table 2).

It should be noted that magnesium alloys have a significant variation of $\mathrm{CC}$ values (45-60\%) operating conditions. As a result, the service life and economic efficiency of protective protection against corrosion of metal structures using magnesium alloys are unpredictable. For this reason, in order to ensure reliable operation of the equipment, periodic diagnostics of the protection system efficiency and timely restoration of the protectors is a prerequisite. It is obvious that the increase and stabilization of the magnesium alloy $\mathrm{CC}$ is an important technical and economic task.

\section{Initial characteristics of magnesium sacrificial alloys}

The research results of the basic electrochemical properties of binary (Figure 1) and ternary (Figure 2) alloys on the basis of magnesium, alloyed with aluminum and zinc are presented below. 
Table 2. Chemical composition (\%) and averaged electro-chemical characteristics of magnesium alloys.

\begin{tabular}{|c|c|c|c|c|c|c|c|c|}
\hline \multirow{2}{*}{ Countries } & \multicolumn{3}{|c|}{ Alloying elements } & \multicolumn{3}{|c|}{ Impurities, no more } & \multirow{2}{*}{$\begin{array}{c}\mathrm{CC}, \\
\%\end{array}$} & \multirow{2}{*}{$\begin{array}{l}-\varphi_{p} \\
\mathbf{m V}\end{array}$} \\
\hline & Al & Zn & Mn & $\mathbf{F e}$ & $\mathbf{C u}$ & $\mathbf{N i}$ & & \\
\hline \multirow{2}{*}{ Russia } & $5.0-7.0$ & $2.0-8.0$ & $0.15-0.50$ & 0.003 & 0.004 & 0.001 & 60 & 1250 \\
\hline & $7.5-9.0$ & $2.0-3.0$ & $0.15-0.50$ & 0.03 & 0.10 & 0.01 & 40 & 1300 \\
\hline \multirow{2}{*}{ England } & $5.3-6.7$ & $2.5-3.5$ & 0.15 & 0.003 & 0.05 & 0.003 & 50 & 1300 \\
\hline & $5.3-6.7$ & $2.5-3.5$ & 0.15 & 0.003 & 0.02 & 0.002 & 50 & 1300 \\
\hline \multirow{2}{*}{ Japan } & $5.3-6.7$ & $2.5-3.5$ & $0.15-0.60$ & 0.003 & 0.02 & 0.001 & 55 & 1300 \\
\hline & $5.3-6.7$ & $2.5-3.5$ & $0.15-0.60$ & 0.03 & 0,05 & 0.003 & 45 & 1300 \\
\hline USA & $5.3-6.7$ & $2.5-3.5$ & 0.15 & 0.03 & 0.02 & 0.002 & 50 & 1300 \\
\hline Germany & $5.8-6.2$ & $2.8-3.2$ & 0.3 & 0.003 & 0.006 & Traces & 55 & 1250 \\
\hline
\end{tabular}

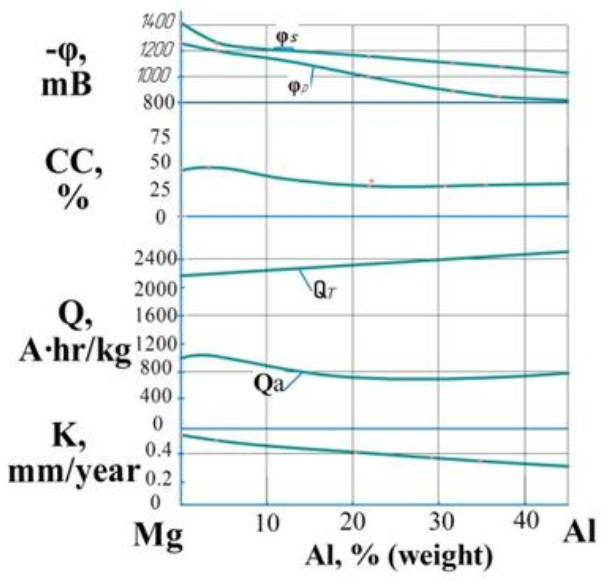

a

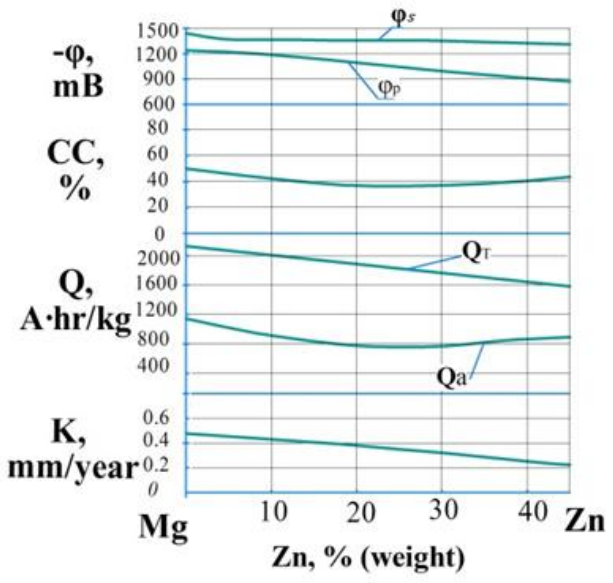

b

Figure 1. Dependence of the main electrochemical properties of magnesium on the content of aluminum (a) and zinc (b).

The analysis of the given data testifies, that magnesium alloys in the field of investigated compositions have heterogeneous structure consisting of grains of a $\alpha$-solid solution of aluminum and zinc in magnesium, intermetallic phases $\left(\mathrm{Mg}_{4} \mathrm{Al}_{3}, \mathrm{Mg}_{3} \mathrm{Al}_{2} \mathrm{Zn}_{2}\right)$ on grain boundaries (Figure 3 ).

It should be noted that the degree of heterogeneity of the structure can vary not only depending on the concentration in aluminum and zinc alloys, but also on the casting conditions influencing the structure of cast magnesium protectors. This can be explained by the non-predictable variation of the $\mathrm{CC}$ values (up to $15 \%$ ), made of one alloy grade and even one melting [10]. 


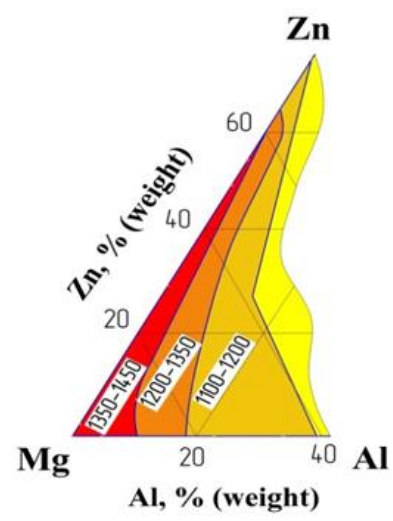

a

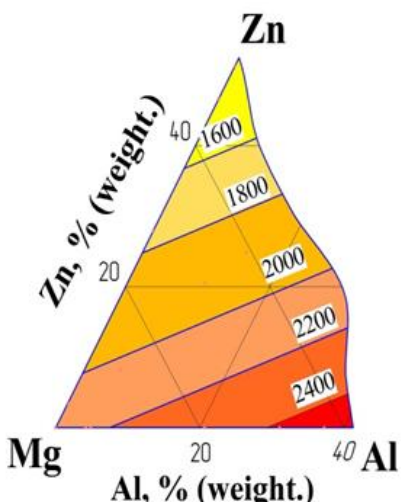

c

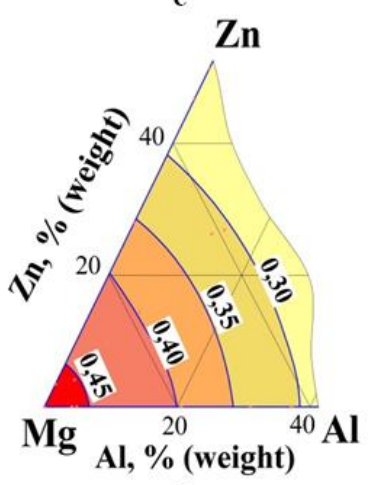

e

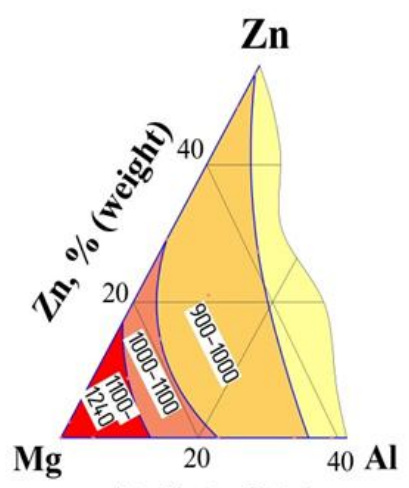

Al, \% (weight)

b

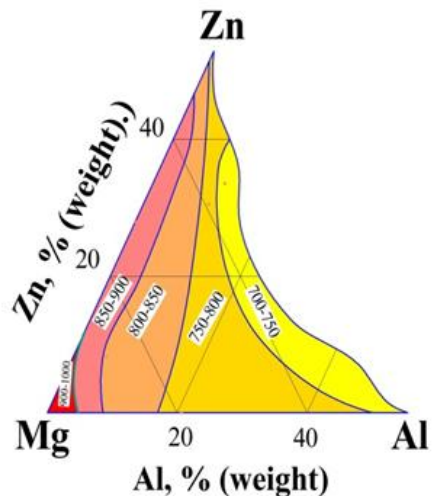

d

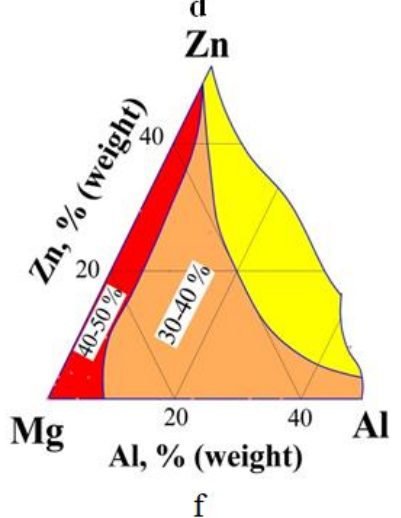

Figure 2. The main electrochemical properties of magnesium alloys of the $\mathrm{Mg}-\mathrm{Al}-\mathrm{Zn}$ system are: $\mathrm{a}$ - stationary potential, $\mathrm{mV} ; \mathrm{b}$ - working potential, $\mathrm{mV}$ (at polarization of current of $\left.5 \mathrm{~mA} / \mathrm{m}^{2}\right) ; \mathrm{c}$ - theoretical current output $\left(Q_{\mathrm{T}}, \mathrm{A} \cdot \mathrm{hr} / \mathrm{kg}\right) ; \mathrm{d}-$ actual current output $\left(Q_{\mathrm{A}}\right), \mathrm{A} \cdot \mathrm{h} / \mathrm{kg}$; $\mathrm{e}-$ corrosion rate, $\mathrm{mm} / \mathrm{year} ; \mathrm{f}-\mathrm{CC}, \%$.

In addition to the main alloying magnesium elements ( $\mathrm{Al}, \mathrm{Zn}$ ), the magnesium sacrificial alloys additionally include elements to enhance technological and mechanical properties while improving the electrochemical characteristics of materials $[10,14,15]$. 


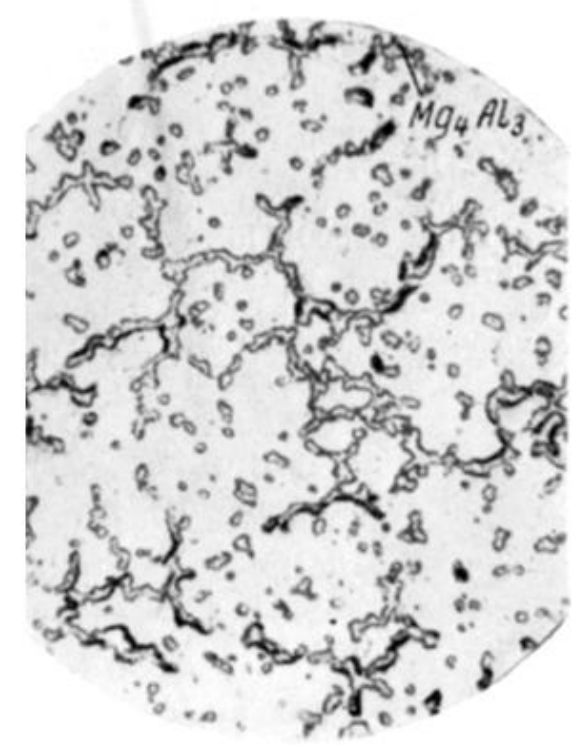

Figure 3. Microstructure (x250) of magnesium alloy in a cast state.

The following are the results of the selection of alloying elements for magnesium, based on the comparison of the inclination of elements to fusion with magnesium, as well as a comparative study of the physical and electrochemical properties of precipitation products account of economic valuation and other characteristics [14]. To reduce their solubility in magnesium (\%) during the formation the structure of $\alpha$-solid solutions built a number of recommended elements: $\mathrm{Cd}$ (100), $\mathrm{Pb}$ (41.7), Sn (14.8), Al (12.7), Zn (8.4), $\mathrm{Li}$ (5.5), Mn (3.4), Ca (1.0), Ce (0.85), Si (0.12) for alloying magnesium.

Analysis of data on theoretical current and electrochemical potential of elements allowed to leave in the group alloying for magnesium alloys. The following elements: Al, $\mathrm{Zn}, \mathrm{Li}, \mathrm{Mn}, \mathrm{Ca}, \mathrm{Ce}, \mathrm{Si}$ are known to have chemical heterogeneity within individual grains of cast metal is the cause of electrochemical heterogeneity. Due to the tendency to intracrystalline liquor, $\mathrm{Ce}, \mathrm{Ca}, \mathrm{Si}$ and $\mathrm{Mn}$ should be considered as auxiliary alloying elements capable of improving the individual characteristics of magnesium alloys. For example, Mn and $\mathrm{Si}$ contribute to the reduction of iron content in magnesium alloys and the grinding of metal grains. Despite the negligible solubility of titanium and zirconium in magnesium, especially in the solid state, they are introduced into the composition of alloys to reduce the content of iron impurity and the crushing of the cast structure [16-17]. Comparing the results of the selection of alloying magnesium elements using different approaches, it is established that the match is obtained by the following elements: $\mathrm{Al}, \mathrm{Zn}, \mathrm{Mn}, \mathrm{Si}, \mathrm{Ca}$.

\section{Chemical purity of magnesium alloys}

Applied sacrificial anodic alloys, having sufficiently close concentrations of alloying components, differ in the content of cathode impurities. The content of metallic impurities, gases and non-metallic inclusions has a significant effect on the actual current output of magnesium alloys and, as a consequence, on the $\mathrm{CC}$ of cast magnesium anodes. Depending 
on the content of cathodic impurities $(\mathrm{Fe}, \mathrm{Cu}, \mathrm{Ni})$ there is a significant change in the actual current output of magnesium (Figure 4).

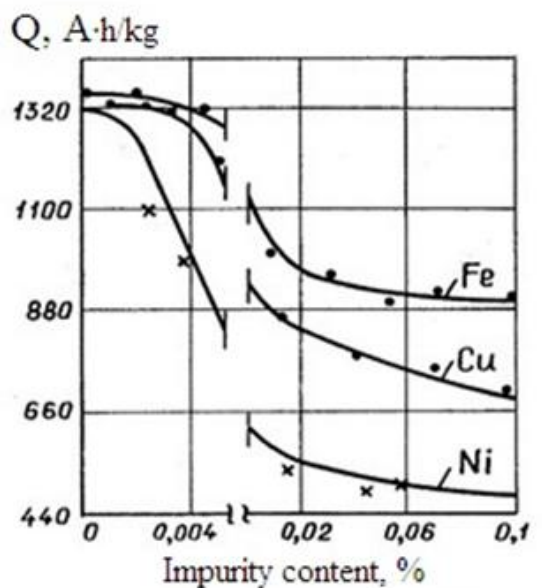

a

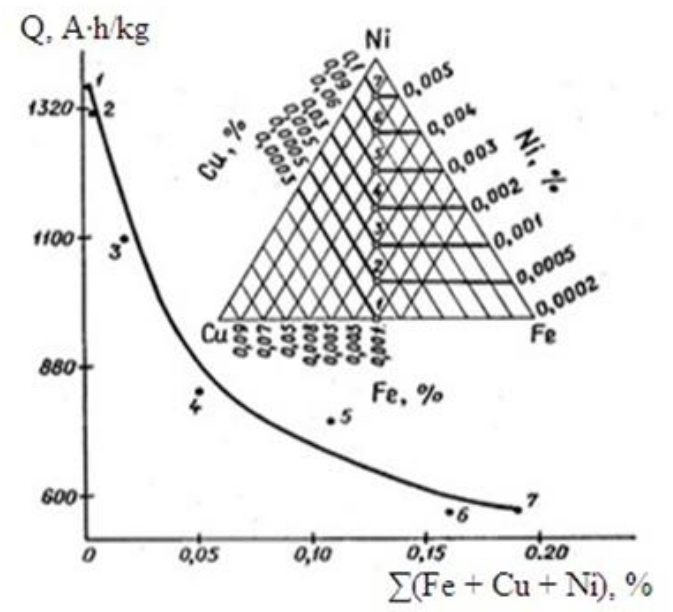

b

Figure 4. The effect of separate (a) and total (b) content of impurities ( $\mathrm{Ni}, \mathrm{Cu}, \mathrm{Fe})$ on the current output value of magnesium.

The above data indicates the need to limit the maximum permissible concentrations of iron, copper and nickel to $0.0035 \%, 0.005 \%$ and $0.001 \%$, respectively. Excess of the contents of these metallic impurities leads to the reduction and dispersion of the $\mathrm{CC}$ of the alloys within 30-40\%.

It was found out an important factor influencing the quality of magnesium alloys is their purity in the content of gas and non-metallic inclusions Figure 5.

According to the established data, the increase of chlorine-ion magnesium content (especially in the electrolytic method of magnesium production and magnesium alloys preparation using chloride salts) from 0.004 to $0.25 \%$ leads to a decrease in actual current output on $10 \%$ (Figure 5a). Increasing the content of hydrogen magnesium (hydrogen accounted for up to $90-95 \%$ of all dissolved gases) from 4.0 to $28 \mathrm{~cm}^{3} / 100 \mathrm{~g} \mathrm{Mg}$ leads to a decrease in its current output from 1340 to $1200 \mathrm{~A} \cdot \mathrm{hr} / \mathrm{kg}$ (Figure 5b).

Increased dispersion of values of actual current output when contained in magnesium chlorine-ion, $0.05 \%$ and hydrogen $>15 \mathrm{~cm}^{3} / 100 \mathrm{~g}$. Metal is caused by uneven distribution of chlorides and formation of gas porosity in the cast alloy. The reduction of current output with the increase of chlorides and hydrogen content can be caused by two factors.

First of all, it can occur as a result of the increased activity of micropores in the formation of sites (foci) containing chlorides, and in the presence of micro-chlorine dependent on the content and distribution of hydrogen. Secondly, the reduction of current output can be caused by the reduction of sample density due to the presence of both chloride and micro-chlorine inclusions. 

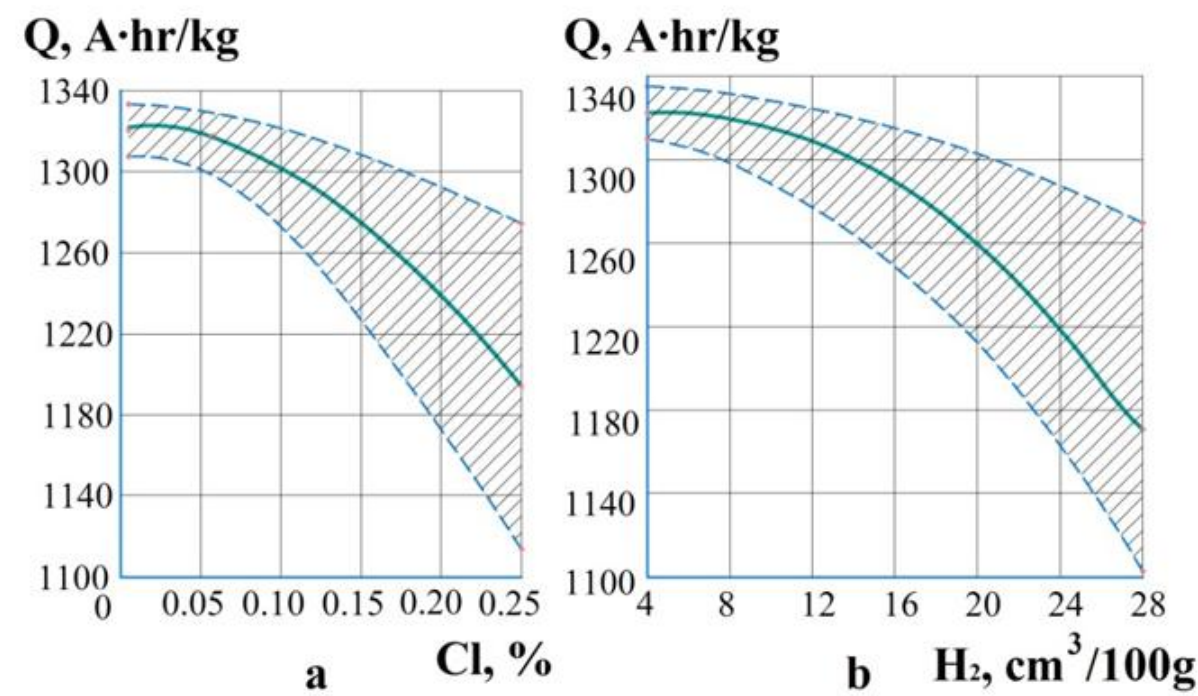

Figure 5. Effect of chloride (a) and hydrogen (b) content on the current output of magnesium.

Oxygen is to be attributed to the non-regulated by standards for magnesium protective impurities. In the magnesium melts oxygen is in the form of suspended oxide inclusions, but in solid magnesium it is in the form as independent phase. Oxide inclusions, changing physic-chemical, technological and mechanical properties, affect the change of electrochemical properties of magnesium. In the real conditions of magnesium and magnesium alloys, production contains of oxygen in terms of magnesium oxide constituting $0.001-0.020 \%$, should be limited to $0.01 \%$.

The presented data on the influence of the chemical purity of magnesium melts (the content of impurity elements) on the values of $\mathrm{CC}$ confirm the need to control the maximum permissible contents not only to regulated by standards components $(\mathrm{Fe}, \mathrm{Cu}, \mathrm{Ni}$ ), but also non-regulated by standards of harmful impurities (chlorine-ion, hydrogen, magnesium oxide).

It is obvious, that for increasing and stabilization of $\mathrm{CC}$ it is necessary to use the high purity magnesium alloys with recommended (Table 3 ) maximum-permissible contents of $\mathrm{Fe}, \mathrm{Cu}, \mathrm{Ni}, \mathrm{Cl}, \mathrm{O}, \mathrm{H}$.

\section{Structure of magnesium alloys}

One of the reasons for the occurrence of electrochemical heterogeneity, defining the $\mathrm{CC}$ of magnesium anodes, is the degree of their structural heterogeneity. The following are the results of research of structure and $\mathrm{CC}$ of magnesium anodic alloy (containing $6.7 \% \mathrm{Al}+$ $2.8 \% \mathrm{Zn}+0.3 \% \mathrm{Mn}$ ) in melted and thermal treated states. The influence of heat treatment on the structure of magnesium alloys was studied on the samples cast in metal form. Thermal treatment of samples was carried out in the muffle furnace. Before loading in the furnace magnesium samples were sealed in ampoules of heat-resistant glass "Pyrex", from which preliminary pumped air to the residual pressure of $1 \cdot 10^{-2} \mathrm{mmHg}$. It was find out that the aging of magnesium specimens at specified temperatures during 1-8 hours with 
subsequent cooling in the air leads to a significant change in the type of the microstructure (Figure 6).

Table 3. Content of harmful impurities (\%) in magnesium and sacrificial anodic alloys (SAA) on its basis.

\begin{tabular}{cccc}
\hline & & \multicolumn{3}{c}{ SAA } \\
\cline { 2 - 4 } $\begin{array}{c}\text { Impurities in the original } \\
\text { magnesium }\end{array}$ & Russian standard & $\begin{array}{c}\text { Suggestions for a group of } \\
\text { impurities }\end{array}$ \\
\cline { 3 - 4 } & & \multicolumn{3}{c}{ no more } \\
\hline $\mathrm{Fe}$ & $0.03-0.05$ & 0.003 & 0.003 \\
\hline $\mathrm{Ni}$ & $0.001-0.002$ & 0.001 & 0.001 \\
\hline $\mathrm{Cu}$ & $0.002-0.02$ & 0.004 & 0.005 \\
\hline $\mathrm{Cl}$ & $0.001-0.5$ & - & 0.005 \\
\hline $\mathrm{O}^{*}$ & $0.001-0.02$ & - & 0.010 \\
\hline $\mathrm{H}^{* *}$ & $3-25$ & - & 15 \\
\hline
\end{tabular}

Note: $\mathrm{O}^{*}-$ Oxygen content in terms of magnesium oxide; $\mathrm{H}^{* *}-$ content of hydrogen, $\mathrm{cm}^{3} / 100 \mathrm{~g} \mathrm{Mg}$.

It has been established that the heterogeneous structure (on the background of $\alpha$-solid solution there are phases $\mathrm{Mg}_{4} \mathrm{Al}_{3}$ и $\mathrm{Mg}_{3} \mathrm{Al}_{2} \mathrm{Zn}_{2}$ typical for the cast state (a), depending on the temperature and duration of exposure goes to almost homogeneous structure (in the background). The dried $\alpha$-solid solution $\mathrm{Al}$ and $\mathrm{Zn}$ in magnesium are visible remains of insoluble phases. The differences of the microstructure of the experimental composition of the alloy change the current output and the CC of magnesium specimens (Figure 7).

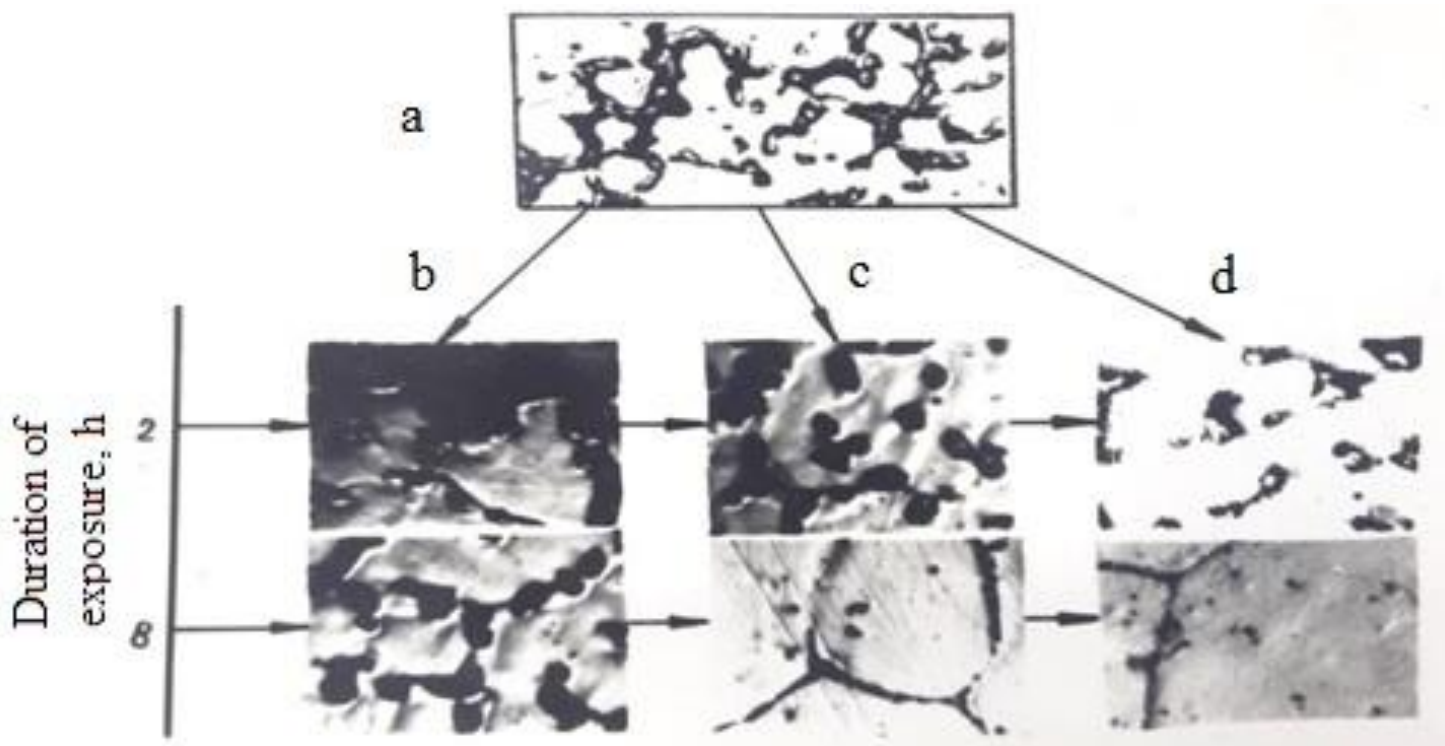

Figure 6. Microstructure (x100) of the magnesium alloy, depending on the heat treatment mode: alloy condition: cast (a); heat-treated shutter during 1-8 hours at 150 (b); 300 (c) and $500(\mathrm{~d}){ }^{\circ} \mathrm{C}$. 


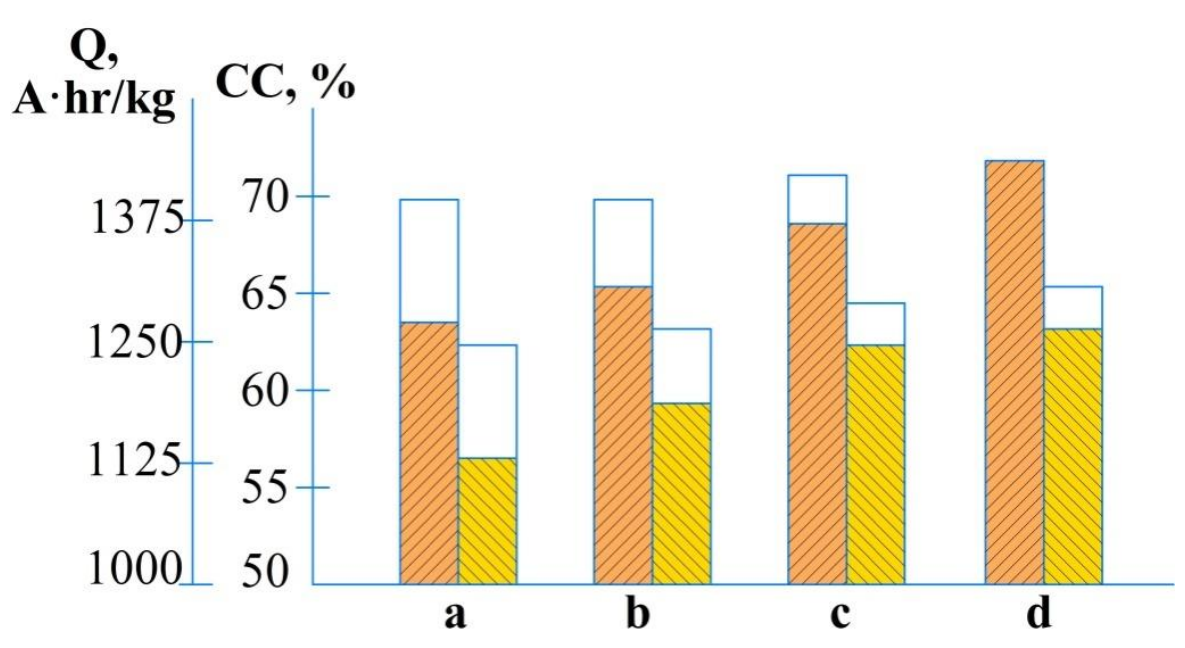

Figure 7. Change of the magnesium alloys current output $Z \square$ and CC $B$ in seawater depending on the heat treatment ( $\square$ - value of scatter values of current output and CC). Alloy condition: cast (a) and heat treated during 8 hr. at 150 (b); 300 (c) and 500 (d) ${ }^{\circ} \mathrm{C}$.

The effect of heat treatment on the standard modes on the structure of the metal is shown in Figure 8. It has been established that if annealing practically does not change the character of microstructure, hardening leads to dissolution of intermetallic phases $\left(\mathrm{Mg}_{4} \mathrm{Al}_{3}\right.$, $\mathrm{Mg}_{4} \mathrm{Al}_{3} \mathrm{Zn}_{3}$ ) with formation of homogenizing single-phase structures. Thermal treatment of aging causes the reverse separation of secondary phases, which are the products of decay of the transmitted metastable $\alpha$-solid solution.

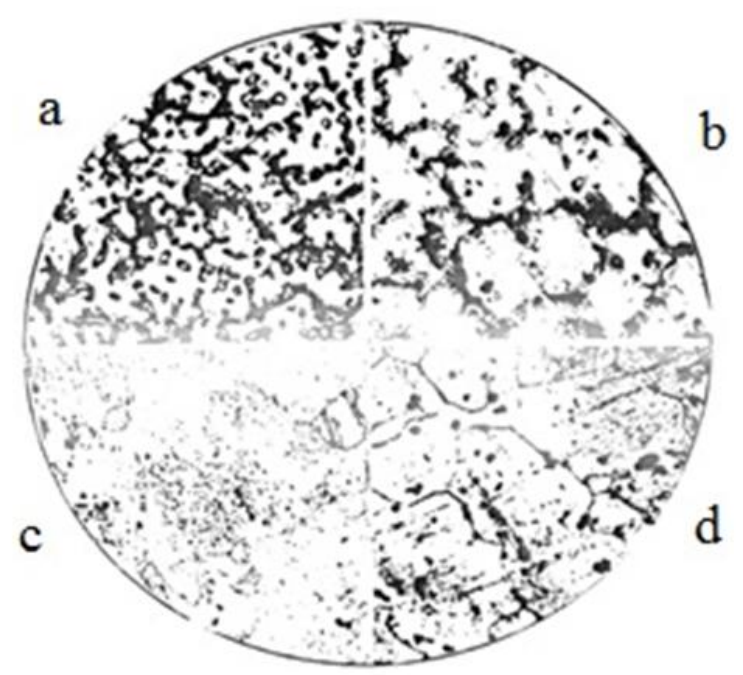

Figure 8. Microstructure (x100) of magnesium alloy depending on the heat treatment mode. The alloys conditions: $\mathrm{a}$ - cast heat-treated by modes: $\mathrm{b}$ - annealing, $\mathrm{c}$ - hardening, $\mathrm{d}-$ aging.

In Figure 9, the presented data on CC samples from magnesium alloy of the skilled composition, processed in various modes of heat treatment. 

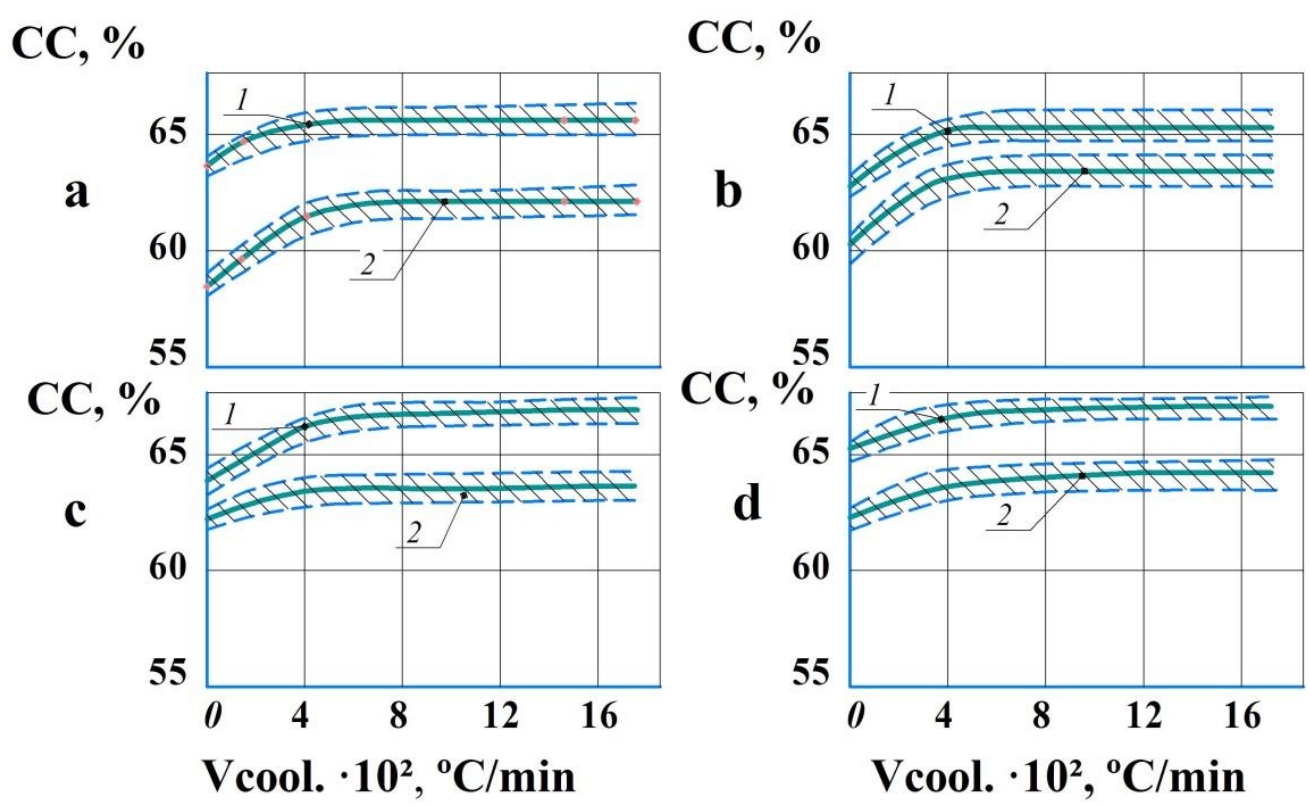

Figure 9. Influence of heat treatment and cooling speed of cast (a) and heat-treated modes: annealing (b), hardening (c) and aging (d) of magnesium alloy samples on CC in soil (1) and seawater (2).

It should be noted that the $\mathrm{CC}$ of alloys tested in soil is on average $3-5 \%$ higher than in seawater. In the Table 4 presented compositions and properties of high purity of $\mathrm{Mg}$-Al$\mathrm{Zn}$ sacrificial alloys, additionally containing $\mathrm{Mn}, \mathrm{Ti}, \mathrm{Zr}$, and rare-earth metals (REM).

Different compositions of alloys on the basis of the Mg-Al-Zn system within the specified limits of alloying elements content practically do not affect the potential changes, $\mathrm{CC}$ and current output at polarization of current of $5 \mathrm{~mA} / \mathrm{m}^{2}$.

Table 4. Composition (\%) and average properties of magnesium alloys.

\begin{tabular}{ccccccccccc}
\hline Alloys & Al & Zn & Mn & Ti & Zr & REM* & $\begin{array}{c}\mathbf{F e}, \\
\text { no more }\end{array}$ & $\begin{array}{c}-\varphi_{\mathbf{s}}, \\
\mathbf{m V}\end{array}$ & $\begin{array}{c}\mathbf{C C}, \\
\boldsymbol{\%}\end{array}$ & $\begin{array}{c}\mathbf{Q}, \\
\mathbf{A} \cdot \mathbf{h r} / \mathbf{k g}\end{array}$ \\
\hline 1 & $5-7$ & $2-4$ & $0.15-0.5$ & - & - & - & 0.004 & 1220 & 61 & 1340 \\
\hline 2 & $5-7$ & $2-4$ & $0.02-0.5$ & $\begin{array}{c}0.001- \\
0.04\end{array}$ & - & - & 0.003 & 1220 & 65 & 1400 \\
\hline 3 & $4-10$ & $0.5-3.0$ & $\begin{array}{c}0.001- \\
0.05\end{array}$ & $\begin{array}{c}0.001- \\
0.05\end{array}$ & - & - & 0.003 & 1220 & 65 & 1400 \\
\hline 4 & $5-10$ & $2-4$ & $0.15-0.5$ & - & $0.005-0.2$ & - & 0.003 & 1220 & 62 & 1380 \\
\hline 5 & $5-10$ & $2-4$ & $0.15-0.5$ & - & - & $0.005-0.2$ & 0.005 & 1220 & 62 & 1380 \\
\hline 6 & $9-10$ & $2-4$ & $0.1-0.5$ & - & $\begin{array}{c}0.005- \\
0.02\end{array}$ & - & 0.003 & 1220 & 64 & 1390 \\
\hline
\end{tabular}

$\mathrm{REM}^{*}$ - rare-earth metal 
Different compositions of alloys on the basis of the $\mathrm{Mg}-\mathrm{Al}-\mathrm{Zn}$ system within the specified limits of alloying elements content practically do not affect the potential changes, $\mathrm{CC}$ and current output at polarization of current of $5 \mathrm{~mA} / \mathrm{m}^{2}$. The introduction of manganese, titanium, zirconium and rare earth elements as microalloying additives provides a reduction in the content of iron impurity and contributes to the grinding of the structure of cast sacrificial materials. It has been established that additional microalloying contributes not only to the increase, but also to the stabilization of the $\mathrm{CC}$ of cast magnesium alloys in sea water. In addition, for all specimens, especially when tested in seawater, there is an increase in the $\mathrm{CC}$ with increased cooling speed of cast sacrificial anodes in the process of their manufacture from 35 to $500^{\circ} \mathrm{C} / \mathrm{min}$. Above this speed, alloys have a small-changing of $\mathrm{CC}$.

\section{Conclusions}

1. The causes of electrochemical heterogeneity associated with the nature of the metal, composition and structure of the protective material have been established.

2. It is shown that the values of $\mathrm{CC}$, which is the most important characteristics of protective magnesium alloys, depend on the chemical composition and purity of the material, as well as on the structure of sacrificial magnesium anodes.

3. In order to eliminate the scatter and stabilization of the values of sacrificial magnesium alloys, it is necessary to ensure not only the control of the maximum permissible contents of cathodic impurities $(\mathrm{Fe}, \mathrm{Cu}, \mathrm{Ni})$, but also the control of the content in the alloys of ad-hoc by the standards of gases (hydrogen) and non-metallic inclusions (Clion, magnesium oxide)-impurities.

4. It has been established that in the production of cast magnesium protectors it is necessary to provide conditions (melting, casting and heat treatment modes) to obtain a homogeneous structure of the metal, providing for all other equal conditions stable values of current capacity.

\section{References}

1. V.A. Kechin and E.Y. Lyublinski, New Sacrificial Anodic Alloys, NACE International, 2018, Phoenix, Arizona, USA, Paper C2018-11388.

2. W. Baeckmann, W. Schwenk and W. Prinz, Handbook of cathodic corrosion protection, Gulf Professional Publishing, 1997.

3. G.H. Koch, M.P. Brongers, N.G. Thompson, Y.P. Virmani and J.H. Payer, Corrosion Costs and Preventative Strategies in the United States, NACE International, 2002, Houston, TX, USA, Paper C2002-2219.

4. P.R. Roberge, Corrosion Basics: An Introduction, Second Edition, 2006.

5. ASTM B843, Standard Specification for Magnesium Alloy Anodes for Cathodic Protection.

6. I.V. Semenova, G.M. Florianovich and A.V. Khoroshilov, Corrosion and corrosion protection, Ed. I.V. Semenova, Moscow, Fizmatlit, 2002, 336 (in Russian). 
7. C. Jennings, A comparison of the structure and Consumption Rate for Centrifugally Cast Anodes Compared with Die-Cast Anodes, NACE International, 2018, Phoenix, Arizona, USA, Paper C2018-10954.

8. E.Y. Lyublinski and V.A. Kechin, Formation of basic properties of galvanic anodes during the industrial production, EUROCORR 2017, Prague, Czech Republic, Paper 72701.

9. V.A. Kechin and E.Y. Lyublinski, New Sacrificial Anodic Alloys, EUROCORR 2016, Montpellier, France, Paper 0-6242.

10. V.A. Kechin, Theory and technology of cast sacrificial materials, Monograph, Vladimir, Editorial and publishing complex of Vladimir State University, 2004, 184 (in Russian).

11. J. Morgan, Cathodic Protection, Second Edition, National Association of Corrosion Engineers, Huston, Texas, 1987, 519.

12. V.A. Kechin, E.Y. Lyublinski, A.V. Kireev and E.S. Prusov, Improvement and stabilization of the electrochemical properties of zinc alloys during casting, Int. J. Corros. Scale Inhib., 2019, 8, no. 1, 69-83. doi: 10.17675/2305-6894-2019-8-1-7

13. V.A. Kechin, E.Ya. Lyublinsky and A.V. Kireev, Effect of gas content on the corrosion and electrochemical characteristics of aluminum protective alloys, Korroz.: Mater., Zashch. (Corrosion: Materials, Protection), 2016, no. 2, 1-6 (in Russian).

14. N.N. Bibikov and E.Ya. Lyublinsky, Corrosion protection of tanks and ballast tanks of oil tankers, Leningrad, TsNIIRumb, 1977, 129 (in Russian).

15. Organization standard 31323949-057-2011, Methods of laboratory testing of the electrochemical properties of sacrificial alloys, Public corporation Gazprom, 2011 (in Russian).

16. M.V. Maltsev, Metallography of industrial non-ferrous metals and alloys, Moscow, Metallurgy, 1979, 364 (in Russian).

17. V.A. Kechin, Selection of elements for preparing magnesium alloys, Shipbuilding Issues, Saint Petersburg, 1986, 46, 71-76 (in Russian).

18. T.A. Zelenitsky, V.A. Kechin and N.K. Ivanov, Protector Anode, Patent No. 2480537, RF, 2011 (in Russian).

19. I.I. Gurieva and M.B. Guchrova, Manufacturing technology and properties of castings and semi-finished products, Handbook, Part 2, 1978, 296 (in Russian).

20. I.P. Vyatkin, V.A. Kechin and S.B. Mushkov, Refining and casting of primary magnesium, M. Metallurgy, 1974, 191 (in Russian). 